\title{
Genetic mapping of autosomal recessive hypotrichosis locus (LAH3), to chromosome 13q14.11-q21.32, in a family from Balochistan
}

Mehwish Durrani ${ }^{1}$, Sheikh Ahmed ${ }^{1}$, Fazal ur Rehman ${ }^{2}$ and Muhammad Ayub $^{1 *}$

1. Institute of Biochemistry, Faculty of Life Sciences, University of Baluchistan, Quetta-Pakistan

2. Department of Microbiology, Faculty of Life Sciences, University of Baluchistan, Quetta-Pakistan

*Corresponding author's email: ayub_2004@ hotmail.com

Citation

Mehwish Durrani, Sheikh Ahmed, Fazal ur Rehman and Muhammad Ayub. Genetic mapping of autosomal recessive hypotrichosis locus (LAH3), to chromosome 13q14.11-q21.32, in a family from Balochistan. Pure and Applied Biology. Vol. 6, Issue 3, pp1053-1060. http://dx.doi.org/10.19045/bspab.2017.600112

\begin{tabular}{llll}
\hline \hline Received: 19/06/2017 & Revised: 29/08/2017 & Accepted: 31/08/2017 & Online First: 05/09/2017 \\
\hline
\end{tabular}

Abstract

Hypotrichosis or alopecia is a medical term used for hair loss deformities i.e. disorders of hair follicles such as the ones occurring during hair formation and/or growth. Localized hereditary hypotrichosis is an autosomal recessive form of non-syndromic alopecia, and the clinical phenotype is sparse hair on the body and axillary areas and can affect both males and females. Till date, four loci for this type of hypotrichosis have been reported which are present on an autosomal chromosomes 18q12.1, 3q27.2, 13q14.11 and 10q12, respectively. Here we present an identified recurrent locus for autosomal recessive form of hypotrichosis, in a family from Lasbella district of Balochistan province, Pakistan. DNA samples from four normal and two affected individuals were used for genotyping and DNA assay with polymorphic microsatellite markers were tested for already identified loci. Analysis of DNA samples with DNA markers D13S153, D13S165 and D13S118, revealed that these markers were heterozygous in normal individuals and homozygous in affected individuals but it established linkage to previously known LAH3locus on chromosome 13q14.11.

Keywords: Hypotrichosis; LAH3; Autosomal recessive

\section{Introduction}

Genetic disorders are caused by anomalies in a gene or an entire part of the chromosome of an individual. There are several human genetic conditions that effect the development and differentiation of epidermal structures including sweat glands, hair, nails, and teeth. Hypotrichosis or alopecia is defined as the structural, growth and developmental abnormalities of hair follicle that results in hair loss. According to the researches, disorders that cause whole or halfway hair loss arise due to the distortions in hair structure, its advancement, and its pathways and flagging particles that influence the hair follicles which subsequently results in hair loss. Malfunctioning of hair emerge either 
secluded or in blend with different imperfections in ectodermal structures, for example, distortions in nails, teeth and sweat organs [1]. Hereditary hair loss is an aggregation of heterogenous disorders pertaining to sparse to complete lack of hair on scalp as well as other parts of body. So far, seven autosomal recessive and equal numbers of autosomal dominant isolated forms have been identified [2].

In mammals there are 3 stages in hair growth cycle which are termed as the developmental phase or anagen, the renewal phase or catagen and the resting phase telogen. At the time of hair advancement, $70-90 \%$ of hair remain in anagen phase for around seven years [3]. Variation in this hair growth stage may bring about malformations of hair cycle for example, alopecial hypotrichosis which results due to abbreviated anagen period.

Hair follicles are made up of various sorts of keratinocytes and trichocytes and are framed by the mutual connection of epithelial and mesenchymal cells maintained among anagen, catagen and telogen. It is known that all hair issues occur due to the deformities in hair follicles during development and progression of hair [4].

Clinically, patients with autosomal recessive hypotrichosis show insufficient eyebrows and/or eyelashes, sparse or wooly hair on scalp, scanty axillary hair as well as on other parts of the body. However, affected show normal beard hair $[5,6]$.

Recent research has identified the genes and loci responsible for hair development and growth cycles that comprise of $\mathrm{HS}$ (hypotrichosis simples; OMIM: 605389) localized to 6p21.3 chromosomes, MUHH; OMIM: 146550 ) residing $8 \mathrm{p} 21$ region, $\mathrm{CA}$ (congenital atrichia; OMIM: 203655) at 8p21, LAH1; OMIM: 607903) at 18q12.1, and $\mathrm{AH}$ (autosomal recessive hereditary hypotrichosis; OMIM: 609167) at 3q27.2 chromosomal positions, respectively.
According to this research, alteration in desmoglein 4 (DSG4; OMIM: 607892), corneodesmosin (CDSN; OMIM: 602593) and hairless gene (HR; OMIM: 225060) results in $\mathrm{LAH}, \mathrm{HS}$ and $\mathrm{CA}$ forms of hypotrichosis [7-12]. Deletion mutation within LIPH (lipase $\mathrm{H}$ ) gene has been identified on 3q27 locus [13] in the $\mathrm{AH}$ region [14].

During this research we have studied a large Pakistani kindred having consanguineous marriage with the phenotypes of autosomal recessive congenital hypotrichosis. The family was first tested for already known loci by typing a polymorphic marker and showed a linkage to known locus LAH3 at chromosome 13q14.

\section{Materials and methods \\ Family History}

The family chosen for this study was from Lasbella district Balochistan and showed signs of autosomal recessive hypotrichosis. Out of six individuals investigated, two male members of the family were affected by this disorder (Figure 1), moreover the likelihood of homozygous transformation was much greater in the family because of cousin marriages.

\section{Genotyping and DNA Isolation}

Blood from all six family members (including the two affected members) was drawn into blood collection tubes and DNA was isolated using standard conventional methods [15]. The purified DNA was later diluted to $40-50 \mathrm{ng} / \mathrm{L}$ via the measurement of its optical density at $260 \mathrm{~nm}$ and then used as a template in polymerase chain reactions (PCR).

For amplification of the markers, standard procedure was used. Final volume of the reaction mixture was kept constant at $25 \mathrm{uL}$ which included 40ng genomic DNA, 200pmol of each primer, 200uM of each deoxy nucleoside triphosphates (dNTP's), 1 unit of Taq polymerase and $2.5 \mathrm{uL}$ of 
reaction buffer (MBI Ferments, York, UK). PCR conditions for 35 cycles were as follows:

$95^{\circ} \mathrm{C}$ (for initial denaturation) $1 \mathrm{~min}$, $95^{\circ} \mathrm{C} 1-\min$, $57^{\circ} \mathrm{C}$ (annealing) $1 \mathrm{~min}$, $72^{\circ} \mathrm{C}$ (extension) $1 \mathrm{~min}$, $72^{\circ} \mathrm{C}$ (final hold) 10 minutes.

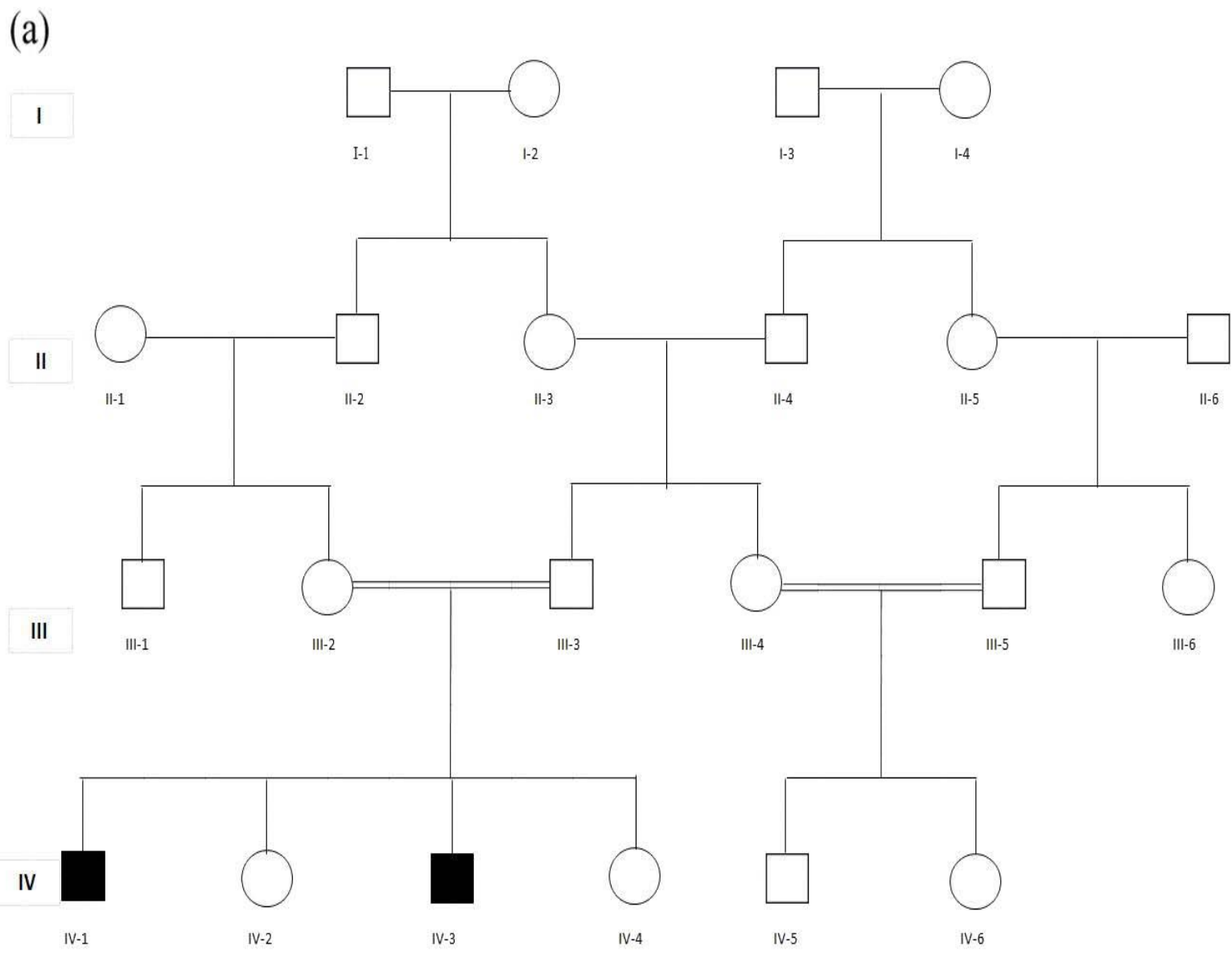

Figure 1. The pedigree of family with hypotrichosis. The squares and circles symbolize, males and females, respectively. The pedigree shows the recessive mode of inheritance. Clear symbols denote unaffected individuals whereas opaque symbols represent affected individuals

The products of PCR were later examined on polyacrylamide gel (i.e. $8 \%$ nondenaturing gel) and visualized on UV Doc to check for size of the DNA fragments obtained.

Microsatellite markers steadily connected with candidate genes were used and linkage examination of the suspected family was performed. Subsequently, with linkage mapping set 10 (Invitrogen Co. San Diego, CA), highly polymorphic markers were applied to carry out the genomic scan. 
Following table 1 represents the list of markers utilized along with their respective loci.

\section{Results}

\section{Clinical findings}

In this study, a family was investigated in which affected subjects demonstrated the features of congenital hypotrichosis. The harrowed individuals showed normal hair growth at the time of their birth but thereafter it hardly regrew when they begin their normal shaving. Moreover, the hair of eye brows, lashes and other body parts also grew scantly in the affected individuals. Nonetheless, these individuals did not show any defects in their nails, teeth and other ectodermal structures and their hearing and sweating ability was also normal. Their immunity as well as skin physiology was also found to be in good condition. It was observed that the individuals who were heterozygous carriers had regular hair growth and were phenotypically similar to non-carriers.

Table 1. Represents the list of markers utilized along with their respective loci

\begin{tabular}{|l|l|l|l|}
\hline \multicolumn{1}{|c|}{ OMIM } & \multicolumn{1}{|c|}{ Position } & \multicolumn{1}{|c|}{ Locus name } & \multicolumn{1}{|c|}{ Markers } \\
\hline 225060 & $8 \mathrm{q} 21$ & HR & $\begin{array}{l}\text { D8S1786, D8S282, D8S560, } \\
\text { D8S290, D8S1048 }\end{array}$ \\
\hline 607892 & $18 \mathrm{q} 12.1$ & LAH1 & $\begin{array}{l}\text { D18S1107, D18S847, D18S478, } \\
\text { D18S36, D18S536 }\end{array}$ \\
\hline 609167 & $3 \mathrm{q} 27.2$ & LAH2 & $\begin{array}{l}\text { D3S2314, D3S1571, D3S3583, } \\
\text { D3S3592, D3S1530, and D3S1262 }\end{array}$ \\
\hline 609239 & $13 \mathrm{q} 14.11-\mathrm{q} 21$ & LAH3 & $\begin{array}{l}\text { D13S328, D13S126, D13S153, } \\
\text { D13S165, D13S118, D13S1807 } \\
\text { and D13S256 }\end{array}$ \\
\hline
\end{tabular}

\section{Genetic mapping of hereditary} hypotrichosis locus

According to the genetic linkage studies of hereditary hypotrichosis, it is well understood that a test should be conducted for some candidate intervals to check the exclusion or linkage before embarking on all genome-wide scan.

In our study, the family was tested for linkage to known loci including DSG4 (LAH1, MIM 607892) gene at 18q12.1, autosomal recessive hypotrichosis (LAH2; MIM 609167) at 3q26.33-q27.3, LAH3 at 13q14.11-21.32, hairless (HR; MIM 225060) gene at 8p21.3 and type II keratin gene cluster (MIM 601928) on chromosome 12 by performing the genotyping of microsatellite markers which were mapped within the linkage intervals of the candidate. To recognize the responsible genes within the family, analysis of linkage was performed by using the DNA samples of the affected and normal individuals. DNA analysis with polymorphic microsatellite markers D13S328, D13S126, D13S153, D13S165, D13S118, D13S1807 and D13S256 revealed that these markers were found homozygous in all the candidates but were found heterozygous in normal candidates, thus establishing the linkage of investigated family to LAH3 locus on chromosome 13q14.11-q21.32. The haplotype of the family is presented here showing the linkage interval.

\section{Discussion}

The family under study with congenital hereditary hypotrichosis were residents of Lasbella district, Balochistan. The individuals in the family were found involved in subsistence agri-business as well as other local businesses. The frequency of intermarriages amongst this particular family was very high indicating an increase of likelihood of hereditary disorders like 
hypotrichosis and a four-generations pedigree chart formulated for this family (Figure 1) using information obtained from 22 individuals including 2 affected males (IV-1 and 1V-3) confirms this notion. Mostly the Pedigree analysis is performed for autosomal recessive traits and their mode of inheritance whereas consanguineous loops account for all the affected people being homozygous for an abnormal allele. During this study, all the affected people were identified to be from the fourth generation while their parents were found phenotypically normal carrying the recessive allele in heterozygous condition.

The affected individuals all showed signs of Hereditary hypotrichosis presenting hair loss only after atleast one week of birth and the ritual head shaving. In adulthood, these affected individuals (Figure 2) had sparse beard hair and a complete loss of body hair, but did not present any defects in nails, teeth, hearing and/or sweating.

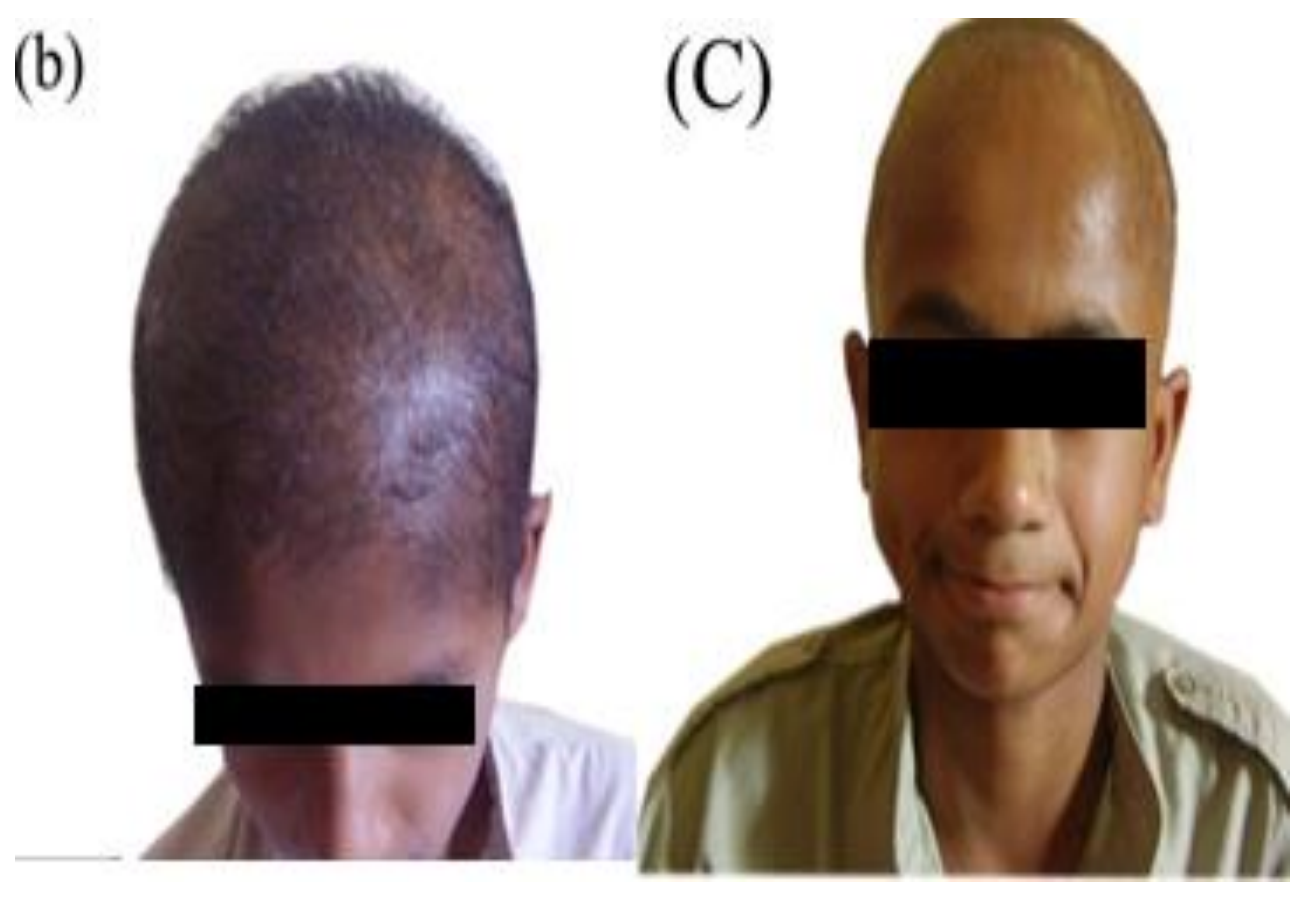

Figure 2. The clinical and physical features of family with hypotrichosis. (b, c) affected individual (IV-1, IV-3) presenting sparse hairs on the scalp as well as sparse eyebrows and eye lashes. (b) affected male individual III- 5 
It was also found out (during the course of this study) that the individuals belonging to the investigated family when tested for linkage to known loci including DSG4 (LAH1, MIM 607892) gene at 18q12.1[11, 12], autosomal recessive hypotrichosis (LAH2; MIM 609167) at 3q26.33-q27.3 [14], LAH3 [16] at 13q14.11-21.32, hairless (HR; MIM 225060) gene at 8p21.3 [8] and the genefor type II keratin cluster (MIM 601928) on chromosome 12were all positive for microsatellite markers, mapped within the individual linkage intervals indicating that this particular phenotype is a result of a mixed genotype and can be due to mutations in any one or multiple locations.

DNA analysis with polymorphic microsatellite markers D13S328, D13S126, D13S153, D13S165, D13S118, D13S1807 and D13S256 (Figure 3) on the other hand revealed that these markers are homozygous in all the affected individuals but are heterozygous amongst individuals presenting normal phenotype. This establishes the linkage of family to already known LAH3 locus on chromosome 13q14.11-q21.32.

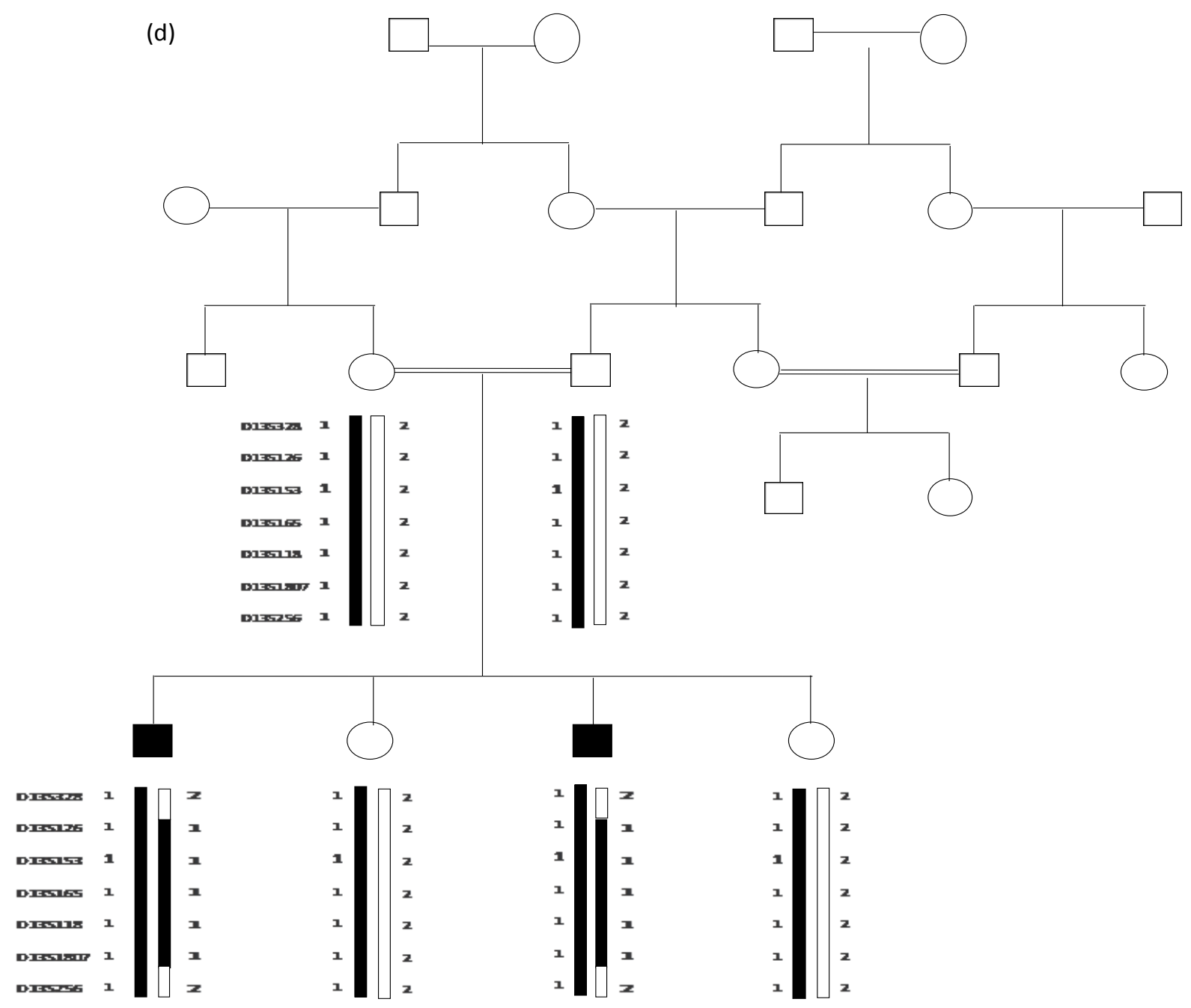

Figure 3. The haplotype of family from Balochistan, the filled block shows the affected allele, while the unfilled block designates the normal individuals. The linked markers D13S126 and D13S256 indicating significant recombination events 


\section{Conclusion}

Analysis of DNA samples, revealed that these markers were heterozygous in normal individuals and homozygous in affected individuals but it established linkage to previously known LAH3locus on chromosome 13q14.11.

\section{Authors' contributions}

Conceived and designed the experiments: $\mathrm{M}$ Ayub, Performed the Experiments: $M$ Durrani, Analyzed the Data: M Ayub, Contributed reagents/ materials/ analysis tools: FU Rehman \& S Ahmed, Wrote the paper: M Durrani.

\section{Acknowledgments}

We thank members of the family involved in the study for their invaluable participation and cooperation. We also thank Higher Education Commission (HEC), Islamabad, Pakistan for their financial support for the study.

\section{References}

1. Tariq M, Ayub M, Jelani M, Basit S, Naz G, Wasif N, Raza SI, Naveed AK, Ullah Khan S, Azeem Z \& Yasinzai M (2009). Mutations in the P2RY5 gene underlie autosomal recessive hypotrichosis in 13 Pakistani families. British Journal of Dermatology 160: 1006-1010.

2. Basit S, Khan S \& Ahmad W (2015). Genetics of human isolated hereditary hair loss disorders. Clinical genetics 88: 203-212.

3. Jones LN \& Steinert PM (1996). Hair keratinization in health and disease. Dermatologic clinics 14: 633-650.

4. Schmidt-Ullrich R \& Paus R (2005). Molecular principles of hair follicle induction and morphogenesis. Bioessays 27: 247-261.

5. Rafique MA, Ansar M, Jamal SM, Malik S, Sohail M, Faiyaz-Ul-Haque M, Haque S, Leal SM \& Ahmad W (2003). A locus for hereditary hypotrichosis localized to human chromosome 18q21. 1. European journal of human genetics 11: 623-628.
6. Ali G, Chishti MS, Raza SI, John P \& Ahmad W (2007). A mutation in the lipase H (LIPH) gene underlie autosomal recessive hypotrichosis. Human genetics 121: 319-325.

7. Levy-Nissenbaum E, Betz RC, Frydman M, Simon M, Lahat $H$, Bakhan $T$, Goldman B, Bygum A, Pierick M, Hillmer AM, Jonca N, Toribio J, Kruse R, Dewald G, Cichon S, Kubisch C, Guerrin M, Serre G, Nothen MM \& Pras E (2003). Hypotrichosis simplex of the scalp is associated with nonsense mutations in CDSN encoding corneodesmosin. Nature genetics 34: 151-153.

8. Ahmad W, Ul Haque MF, Brancolini V, Tsou HC, Ul Haque S, Lam H, Aita VM, Owen J, Frank J, Cserhalmi-Friedman PB \& Leask A (1998). Alopecia universalis associated with a mutation in the human hairless gene. Science 279: 720-724.

9. John P, Aslam M, Rafiq MA, Haque S \& Ahmad W (2005). Atrichia with papular lesions in two Pakistani consanguineous families resulting from mutations in the human hairless gene. Archives of dermatological research 297: 226-230.

10. John P, Tariq M, Rafiq MA, Muhammad D, Waheed I, Ansar M \& Ahmad W (2006). Recurrent intragenic deletion mutation in desmoglein 4 gene underlies autosomal recessive hypotrichosis in two Pakistani families of Balochi and Sindhi origins. Archives of dermatological research 298: 135-137.

11. Kljuic A, Bazzi H, Sundberg JP, Martinez-Mir A, O'Shaughnessy R, Mahoney MG, Levy M, Montagutelli X, Ahmad W, Aita VM \& Gordon D (2003). Desmoglein 4 in hair follicle differentiation and epidermal adhesion: evidence from inherited hypotrichosis and acquired pemphigus vulgaris. Cell 113: 249-260. 
12. Rafique MA, Ansar M, Jamal SM, Malik S, Sohail M, Faiyaz-Ul-Haque M, Haque S, Leal SM \& Ahmad W (2003). A locus for hereditary hypotrichosis localized to human chromosome 18q21. 1. European journal of human genetics 11: 623-628.

13. Kazantseva A, Goltsov A, Zinchenko R, Grigorenko AP, Abrukova AV, Moliaka YK, Kirillov AG, Guo Z, Lyle S, Ginter EK \& Rogaev EI (2006). Human hair growth deficiency is linked to a genetic defect in the phospholipase gene LIPH. Science 314: 982-985.

14. Aslam M, Chahrour MH, Razzaq A, Haque S, Yan K, Leal SM \& Ahmad W (2004). A novel locus for autosomal recessive form of hypotrichosis maps to chromosome 3q26. 33-q27. 3. Journal of medical genetics 41: 849-852.

15. Grimberg J, Nawoschik S, Belluscio L, McKee R, Turck A \& Eisenberg A (1989). A simple and efficient nonorganic procedure for the isolation of genomic DNA from blood. Nucleic acids research 17: 8390-8390.

16. Wali A, Chishti MS, Ayub M, Yasinzai M, Ali G, John P \& Ahmad W (2007). Localization of a novel autosomal recessive hypotrichosis locus (LAH3) to chromosome 13q14. 11-q21. 32. Clinical genetics 72: 23-29. 